\title{
La pregunta por el lugar del arte en el mundo contemporáneo o cómo acercarse a una idea de "arte otro"1
}

\section{The question of the place of art in the contemporary world or how to approach an idea of "art other"}

\author{
Mgter. Jorge Wilson Gómez Agudelo \\ Universidad del Tolima (Colombia) \\ jwgomeza@ut.edu.co
}

Recibido: 29 de julio de 2013

Aceptado y Publicado: 29 de septiembre de 2013

\section{Resumen}

El presente documento tiene como referencia las dinámicas de las relaciones sociales contemporáneas. Desde una lectura crítica de las formas de representación, esta investigación presenta reflexiones sobre los lugares del arte hoy. Varias perspectivas conceptuales que han acompañado el proceso investigativo, proponen la contemporaneidad como espacios diseñados para el consumo, es decir, espacios en los que no se puede hacer lugar. Así mismo, se presentan reflexiones sobre las maneras en que las industrias culturales han configurado formas de expresión homogeneizadas pero han abierto también formas de mixtura que dinamizan la creación. ¿Tendrá lugar el arte en estas dinámicas de globalidad del consumo?, ¿Qué entendemos por lugar para el arte?, ¿Qué arte podría hacer lugar en américa latina? Desde estas preguntas, el proceso de investigación presenta prácticas culturales que complejizan los límites entre el arte y las prácticas estéticas. Además se aborda la categoría de heteropía y las posibilidades de pensar a américa latina como expresión de interculturalidad.

\section{Abstract}

This document is referenced to the dynamics of contemporary social relations. From a critical reading of the forms of representation, this research presents reflections on our art today.

\footnotetext{
1 Artículo producto de una Ponencia presentada en el VI Encuentro Panamericano de Comunicación COM PANAM 2013 celebrado la Escuela de Ciencias de la Información de la Universidad Nacional de Córdoba (Argentina), durante los días 5, 6 y 7 de junio de 2013.
} 
Several conceptual perspectives that have accompanied the investigative process, proposed as contemporary spaces designed for consumption, that is, spaces that can not be done instead. It also presents reflections on the ways in which cultural industries have configured homogenized forms of expression but have also opened ways to streamline the creation mixture. Will place the art in these dynamics of consumption globality, What do we mean by place for art, What art could make room in latin america? From these questions, the research process presents cultural practices that complicate the boundaries between art and aesthetic practices. It also addresses the category of heteropía and possibilities of thinking and expression latin america multiculturalism.

Palabras Clave: arte, lugar, espacio político, consumo.

Key Words: Art; Instead, political space; consumption.

\section{Imagen 0: pregunta sobre la pregunta}

¿Desde que lugar enuncio la pregunta? ¿Por qué enunciar un título de una conferencia se define como "La pregunta por el lugar del arte"? Adicionalmente por qué complementar un título diciendo: "cómo acercarse" y finalizar la pregunta diciendo: "a una idea de arte otro". ¿Debe tener lugar el arte? ¿Para qué y por qué debe tener lugar?

El signo de interrogación es siempre un eje de tensión. Pone en consideración algo que debe ser pensado, es siempre un punto de inflexión que supone ubicar algo que cabe en el pensamiento. Enuncia una preocupación, una ruptura de la certeza. Mi lugar es entonces inicialmente el faro que observa en la penumbra, una suerte de interpelación del saber como dado (es decir, un saber que presupone aspectos incuestionables) que nos pone en condición de pensar cómo se ha estructurado el mundo contemporáneo, o mejor, lo que suponemos es ese mundo y desde allí acercarnos al lugar del arte.

Cuando digo "acercarse" estoy planteando otro eje de tensión. ¿De qué he estado alejado? Si me acerco a algo, implica que hay un desplazamiento de un lugar a otro, que está aconteciendo un movimiento de eje, es decir, una tensión adicional que me ubica cerca de algo que no es en sí un lugar específico sino cerca de él. ¿Qué es esta idea de "arte otro" que está cerca cuando abordo el problema por el lugar del arte? 


\section{Imagen 1: Perdidos en el espacio}

Partiré entonces de este primer asunto: el lugar es una enunciación y un asunto de espacio.

Desde Aristóteles, Newton, Heidegger, Foucault, Duque (entre muchos otros) se han planteado diversos conceptos para intentar acercarse al problema del espacio. Nos referiremos a ellos inicialmente para plantear dicho problema. Aristóteles por ejemplo, consideraba el espacio como aquello que posee cualidades de ordenación y que es identificable por medio de un nombre. Es decir, sabemos que una mesa de conferencias desde la cual se enuncia ésta, se ubica frente a un grupo de personas que escuchan y que algunas de estas personas pueden estar un poco más arriba o más atrás, que hay otras afuera del recinto, etc. En conclusión la ordenación de estos espacios permite relacionarnos y comunicarnos de maneras efectivas porque nombramos de alguna manera "los espacios". Por su parte Newton, entendía el espacio como contenedor de la totalidad de los objetos materiales y responde a la idea de absoluto inmóvil y uniforme, es decir, todo es espacio. Con Einstein estas dos ideas anteriores se redefinen pues él concebía el espacio como un campo tetradimensional que además es relativo. La cuarta dimensión característica del espacio es el tiempo y no puede existir entonces un espacio independiente de ese tiempo. Para Heidegger, "El hombre existe en el espacio al dar lugar al espacio, y en cuanto que "ya de siempre ha dado lugar (eingerdumt) al espacio»" (Duque 2001: 13). En Foucault (1967) el espacio es entendido como "emplazamiento" y propone en esta categoría la relación entre las utopías (emplazamientos sin lugar real) y las heterotopías (emplazamientos otros que definen los demás espacios). Duque por su parte, problematiza el planteamiento de Heidegger y plantea que los espacios nunca son neutrales por lo que todo espacio es político.

La relatividad del espacio en este sentido estaría definida por muchos factores pero enunciemos sólo dos para abrir un poco más la discusión.

1. Cuando digo, las personas están frente a quien enuncia una charla y no en "otro espacio" diferente, puede ser que se relativice dicha relación ya que no es la experiencia de unos cuerpos lo único que determina nuestra existencia particular. Por ejemplo, si esas personas poseen objetos electrónicos que les permite estar conectados en ese mismo momento a la red, este espacio que se ocupa está interceptado por las relaciones tejidas colectivamente con otros espacios que 
interactúan simultáneamente. Por otro lado, pensemos en el ejercicio que emprendí para la escritura de este artículo. Estoy narrando en el presente que me determina estar frente a ustedes como lectores contingentes pero este ha sido un ejercicio anterior desarrollado en otro espacio que me permitió, simular en pasado, el espacio virtualizado ${ }^{2}$ que hoy ocupamos como reflexión sobre los espacios.

2. Este espacio que conocemos está inserto en unas tensiones que lo hacen participe de un mundo complejo que hace de la mirada de cada quien, una posibilidad de definición. Es decir, cada forma de llegar a ese espacio hace de él una plétora de sentidos. ¿Han pensado en la motivación o accidente que hace posible que cada persona asista? Sin embargo, este es un espacio definido por unas características que lo excluyen de otros. Por ejemplo aquellos en los que acontecen intercambios puramente comerciales y que no dejan espacio a la interacción o a la negociación de diferencias. Pensemos por ejemplo en algún cinema. Allí aparece el "entretenimiento" vendido como mercancía que le define unas maneras particulares de relación. Si quisiéramos discutir lo mala que fue la película, tendríamos que desplazarnos a "otro espacio" que nos permitiera discutir tales asuntos. En resumen, son espacios en los que no es posible la socialización más allá de los efímeros intercambios propios del encuentro.

Así pues, en el primer ejemplo encontramos una idea de un espacio desterritorializado que nos lleva a una reflexión importante. Las ciudades tal como hoy las concebimos son espacios polisémicos complejos en tanto no están reducidas a condicionamientos espaciales. Javier Echavarría (1994) en un texto impresionante refiere la experiencia de transformación de las ciudades desde la Polis griega, pasando por las ciudades medievales, las renacentistas, las metrópolis industrializadas, las cosmópolis que refieren una ciudadanía modernizada, las megalópolis que conurban pequeñas poblaciones aledañas y demandan cada vez mayor uso de energía, hasta las telépolis que son ciudades desterritorilizadas en función de un espacio global o un espacio mundo. Esto empieza entonces a orientar un poco la pregunta de nuestra reflexión.

En el segundo ejemplo encontramos un elemento clave para acercarnos al problema pretexto. Con Bauman (2006) se proponen dos categorías de espacio público a saber:

1. Las plazas: Lugares inhóspitos que inspiran respeto pero desalientan la permanencia, pero además espacios en los que se hace imposible compartir con extraños. "Los

\footnotetext{
${ }^{2}$ Respecto de las reflexiones sobre la virtualidad el texto de Pierre Levý ¿Qué es lo Virtual? es un referente importante. Hablo aquí de la edición de Paidós de 1999. 
edificios de formas fantásticas que rodean la enorme plaza vacía están hechos para ser mirados, no para entrar en ellos: envueltos de arriba abajo en cristal espejado, no parecen tener ventanas ni puertas de acceso abiertas a la plaza" (Bauman 2006: 104). Lugares que, siguiendo a Levi Strauss, enuncia además como espacios interdictorios o espacios émicos, espacios que eliminan al otro.

Consistía en "vomitar", expulsando a los otros considerados irremediablemente extraños y ajenos: prohibiendo el contacto físico, el diálogo, el intercambio social y todas las variedades de commercium, comensalidad o connubium. Hoy, las variantes extremas de la estrategia "émica", son, como siempre, el encarcelamiento, la deportación y el asesinato. Las formas superiores y "refinadas" (modernizadas) de la estrategia "émica" son la separación espacial, los guetos urbanos, el acceso selectivo a espacios y la prohibición selectiva de ocuparlos (Bauman 2006: 109)

2. Los templos del consumo: especialmente cafeterías, shoppings, teatros, sitios turísticos que invitan a actuar pero no a interactuar. "La tarea es consumir, y el consumo es un pasatiempo absoluto e irremediablemente individual, una cadena de sensaciones que sólo puede ser experimentada -vivida- subjetivamente" (Bauman 2006: 104). Estos espacios para el consumo, espacios fágicos, espacios que eliminan la diferencia del otro, tienen la característica de movilizar una estrategia de convertir en idénticos a mí a quienes poseen la categoría de otro.

(...) "ingerir", "devorar", cuerpos y espíritus extraños para convertirlos, por medio del metabolismo, en cuerpos y espíritus "identicos", ya no diferenciables, al cuerpo que los ingirió. Esta estrategia revistió también un amplio espectro de formas: desde el canibalismo hasta la asimilación forzosa -cruzadas culturales, guerras de exterminio declaradas contra las costumbres, calendarios, dialectos y otros "prejuicios" y "supersticiones locales" -. (Bauman 2006: 109)

En estas perspectivas aquello que se entiende como colectivo, no tiene nada de colectivo pues es imposible socializar. Foucault lo comprende muy bien y abre el asunto para pensar el concepto de heterotopías (a diferencia de las utopías como lugares sin lugar) en las que se instaura una virtualidad contingente mientras se habita. Esta virtualidad contingente determina todos los demás espacios que nos definen y por ellos circulan discursos y formas de poder que no son visibles, en otras palabras, son formas de poder micro que se instauran en el sujeto como verdad incuestionable "es que así es y ha sido siempre". Nos entregamos a los brazos del consumo en estos lugares determinando nuestra existencia sin que 
tengamos claridad sobre las formas en que operan los discursos sobre el consumo. Pero para problematizar un poco más la cuestión del espacio, Bauman añade dos categorías adicionales que me interesa resaltar:

1. No lugares: espacios de tránsito en los cuales sentirse como en casa sin comportarse como en casa.

2. Espacios vacíos: espacios que invisibilizan al otro y su otredad. Espacios definidos por mapas mentales excluyentes. Vacíos en el ojo y cuerpo de quien los desconoce.

Hemos llegado pues a un asunto importante en nuestra reflexión. La pregunta por el lugar en esta perspectiva es múltiple: Por un lado ¿qué es un lugar en toda esta perspectiva?, ¿por qué ocupar el tiempo pensando esta idea del lugar?, ¿por qué preguntarse por lugares nos daría pistas para entender o mejor acercarnos a la idea de un arte otro?, ¿qué entender por otro inicialmente para poder pensar esta idea en el arte?, ¿por qué mirar este asunto desde un lugar que planteamos como arte?

\section{Imagen 2: Pausa necesaria para encontrarnos}

Hagamos entonces un primer acercamiento para adentrarnos en el problema que emprendimos:

¿Qué es un lugar?: Un acto es un territorio, o mejor, un territorio es "el acto mediante el cual se extraen fragmentos de los medios circundantes para componer un paisaje melódico poblado por personajes rítmicos" (Moreno 1998: 14) Pero para que sea un acto, es necesario que acontezca algo telúrico que logre que a quienes entre-tiene experimenten un estado en el que constituyan hábito, pues la memoria se funda con el hábito y a fuerza de repeticiones, las prácticas sociales se convierten en eso: un hábito) Para constituirse pues como lugar, es necesario que las prácticas permitan continuidad de hábito. $Y$ decimos esto pues toda práctica es producto del territorio que la funda, territorio que por demás "se compone de límites elásticos, flexibles, negociables, constituidos por la conducta de sus ocupantes (...) que cabe llamar etogramas" (Pardo 1991: 18). Así pues, todo lugar se compone de ligazones que la comunidad perpetua a través de permanentes reactualizaciones en que el individuo queda fusionado en la comunidad que le da sentido. Los territorios están configurados por personas (personajes rítmicos diríamos con DeleuzeGuattari) que desempeñan papeles diversos que entran y salen, que constituyen ritos (en su sentido más amplio) para rememorar el mito que da origen al lugar. Pero esta fundación de 
la que damos cuenta no es una tal que pretenda leerse en términos de inicio (aquel que también permite establecer un fin), pues origen como aquí lo entendemos es más una experiencia de invención (in-venire, traer de alguna parte, reconfigurar).

Así pues, se fundan territorios cada vez que las manadas se encuentran y estos territorios una vez fundados permiten hacer lugar. Ese en el que puede tener sentido vivir. Pero no hay que olvidar que hablamos de territorios en el seno de las relaciones urbanas que antes describíamos. El lugar en resumen es tal por la posibilidad de ser dotado de sentido, sin embargo, estos sentidos múltiples característicos de nuestro presente, son reducidos por las lógicas contemporáneas descritas anteriormente. Las tensiones o maneras de resistir son los lugares propios del arte y otras experiencias políticas. Nótese que al expresar "otras experiencias políticas", estoy asumiendo que el arte es de entrada una experiencia política. ¿Por qué subrayar esta concepción del arte y además establecer que existen otras experiencias que cumplen un papel similar al arte? Sin embargo, mi propuesta emprende una mirada sobre la noción de un "arte otro" que quisiera no perder de vista. Pero primero iremos a esta idea de arte como asunto político para arribar o acercarnos a la promesa de comprender un "arte otro".

\section{Imagen 3: Lo residual}

Bauman (2005) es quien también abre una inquietante cuestión sobre las condiciones en que la modernidad liviana o modernidad líquida ha configurado las relaciones de poder. En el capitulo 2 del libro en mención, titulado “¿Son ellos demasiados?”, visibiliza la manera en que persiguiendo la idea del progreso, occidente construyó al "otro" como una noción de "ellos" "los macilentos, retrasados e irresolutos o decadentes y degenerantes ocupantes del globo" (Bauman 2005: 52), en contraposición con "nosotros" los modernos, civilizados y por tanto más verdaderos que "ellos". Pero lo que me interesa destacar aquí es cómo la estrategia fágica que describíamos anteriormente, como aquella en la que se elimina la "otredad" del otro, se sutilizó lentamente ${ }^{3}$, por supuesto después de varios siglos de guerra inmisericorde.

\footnotetext{
${ }^{3}$ Cabe aclarar que la estrategia émica, sigue operando de manera sistemática aún en pleno siglo XXI. Por supuesto no en la condición de exterminio masivo pero si en la condición de exterminio selectivo que mina la capacidad de resistencia de los pueblos. Al respecto pueden profundizarse noticias como la del 18 de abril de 2013 que anuncia la muerte a manos de encapuchados del líder indígena Benancio Taquinás de la vereda Barondillo en Jambaló Cauca, Colombia. Recuperado de
} 
(...) el exterminio de los indígenas con el fin de despejar nuevos lugares para el excedente de población europeo (esto es, la preparación de los lugares a modo de vertedero, para los residuos humanos que el progreso económico doméstico estaba arrojando en cantidades crecientes) se llevó a cabo en nombre del mismísimo progreso que reciclaba el excedente de europeos en «emigrantes económicos» (Bauman 2005: 55)

Es decir, poco a poco se establecieron estrategias que eliminaron de la contienda la pregunta por la diferencia y en las lógicas de la multiculturalidad, abrieron escenarios de reconocimiento invisibilizante. En otras palabras, reconocer que el otro existe porque es muy parecido a mí y podemos construir un proyecto político que en realidad es mí proyecto político. Es el ejemplo de la constitución política de 1991 en Colombia que reconoce el país como un territorio pluriétnico pero en el que las discusiones sobre los destinos de la nación son hegemonizantes tras la subsunción del punto de vista "otro" en las decisiones de las aparentes mayorías. Pongamos un ejemplo: hace muy pocos días se discutió en el congreso de la República la decisión de otorgar plenitud de derechos a matrimonios igualitarios o lo que es lo mismo, matrimonios entre personas del mismo sexo. Esta discusión tuvo muchas polarizaciones y se decidió en las votaciones 51 en contra frente a 17 a favor. Es por ello que la decisión de construir proyectos interculturales se reduce a decisiones de mayorías y no a decisiones donde la otredad del otro entra en consideración.

Pero estas lógicas de eliminación de la otredad del otro, no podrían haberse gestado sin que las lógicas de representación se instauraran con formas de comprender la realidad. Este es precisamente el debate sobre las dinámicas de las industrias culturales. Desde esta perspectiva podemos visualizar una característica fundamental de la condicionante sociedad contemporánea. Se trata de una sociedad en la que prevalece el homo consumens que produce además dos categorías de humanos el homo relictum y el homo opulenti. Este homo relictum, es de quien me ocupo en esta tercera imagen-reflexión. En otras palabras,

En una sociedad de consumidores, se trata de «consumidores fallidos», personas que carecen del dinero que les permitiría expandir la capacidad del mercado de consumo, en tanto que crean otra clase de demanda, a la que la industria de consumo orientada al beneficio no puede responder ni puede «colonizar» de modo rentable. Los consumidores son los principales activos de la sociedad de consumo; los consumidores fallidos son sus más fastidiosos y costosos pasivos. (...) La «población

http://www.nasaacin.org/nuestra-palabra-kueta-susuza/5662-accion-urgente-por-asesinato-del-lider-indigena-de-jambalo-yotras-violaciones-a-los-ddhh-en-colombia. Fecha: 29/04/13. 
excedente» es una variedad más de residuos humanos. (...) Se trata más bien de «victimas colaterales» del progreso económico, imprevistas y no deseadas (Bauman 2005: 57).

Y continúa diciendo:

Las naciones ricas pueden permitirse una alta densidad de población porque son centros "de alta entropía» que extraen recursos, muy en especial las fuentes de energía, del resto del mundo, y devuelven a cambio los residuos contaminantes y con frecuencia tóxicos del procesamiento industrial que agota, aniquila y destruye una gran parte de las reservas energéticas mundiales. La población de los países opulentos, relativamente escasa para los estándares planetarios, representa en torno a los dos tercios del uso total de energía. ¿No somos nosotros -los ricos, los despreocupados consumidores de los recursos del planeta- los auténticos «parásitos», «gorrones» y «sableadores» planetarios? ¿Acaso no es preciso hacer remontar a «nuestra gloriosa forma de vida» - que nuestros portavoces políticos declaran que «no es un asunto negociable» y que juran defender con uñas y dientesla fertilidad «excedente» 0 «excesiva», a la que hacemos responsable de la «superpoblación» del globo? (Bauman 2005: 62).

Estas ideas hacen de nuestras inquietudes una lectura preocupada por el lugar en tanto los espacios despojados en los que difícilmente puedan labrarse lugares, son externalidades propias de un sistema incapaz de encargarse de sus propias monstruosidades. Muchas de las condiciones en que se genera esta residualidad, pertenece a una pretendida intensión de unificación por la que pasa el concepto de multiculturalismo. Todo multicultural es bienvenido cuando entra en las condiciones del mercado pero es desechado en cuanto representa un punto de vista otro que reclama una manera distinta de pensarse y sentirse habitante de un lugar propio en el mundo. En este sentido, es importante mirar los aportes de Arturo Escobar en su texto "Más Allá del Tercer Mundo: Globalización y Diferencia" en el que postula una crítica al proceso de globalización y su consecuente proyecto de concentración del capital.

No sólo no es inevitable el modelo de globalización presente, sino que es posible postular la idea de que la globalización devenga en un pluriverso, es decir, en un espacio plural donde, al decir del sub-comandante Marcos, muchos mundos sean posibles, y con la salvedad de que estamos hablando de mundos en plural, es decir, una verdadera multiplicidad de configuraciones político-culturales, diseños socioambientales y modelos económicos (Escobar, 2005:11). 
Es por ello que las formas de operación de la industria cultural (pero más aún de las industrias creativas), legitiman un discurso unilateral que por supuesto se encuentra al servicio del mercado, es decir, al servicio del homo consumens. Basta con pensar las dinámicas de la industria de la televisión. Su foco de acción es el templo del consumo, desconociendo lo que técnicamente conocemos como costos externalizados, es decir, los costos que asumen los trabajadores del mundo excluido a través de la pauperización de sus salarios, la inexistencia de su seguridad social y la casi eliminación de sus oportunidades para el ocio. ¿Qué arte puede caber aquí? ¿Para qué poetas en tiempos de misería? Se preguntaría Hölderlin.

En las indagaciones que hemos desarrollado, hemos podido encontrar algunas acciones que nos parecen capitales para problematizar estas discusiones sobre las lógicas de la industria cultural. Por un lado, acciones como las creative commons son experiencias políticas que pretenden pluralizar el acceso al mundo simbólico pero que también posibilitan que "otros" diversos promuevan, visibilicen y dinamicen sus formas de cultura. Si las formas de creación dejan de estar subsumidas a la lógica "todos los derechos reservados", es más probable que la creación se ponga en condición de encarar resistencias potentes que enfrenten el discurso de la carencia. Pero dejare para nuestra última imagen algunas perspectivas interesantes que quisiera poner como acercamiento a un "arte otro".

\section{Imagen 4: Arte, ¿líquido?}

En un texto de 2007, que tiene por título Arte, ¿líquido?, Bauman aborda dos ideas importantes: por un lado la idea de cómo desde el arte se cuestiona nuestra condición de mortalidad inevitable y cómo se cuestionan las verdades absolutas.

En esta etapa líquida del proceso de modernización, el homo consumens se caracteriza por el deseo permanente de desear sin cumplir todos sus deseos a cabalidad. Lo líquido en el arte se entendería como el proceso a través del cual la obra se convierte en acontecimiento, como aquello que irrumpe pero se agota también, se consume. Su función se establece en el intersticio de la mortalidad que devela pero en su incapacidad de inmortalizarse. Bauman (2007) retoma la idea de lo líquido en el arte y a partir de la obra de 4 artistas: Gustav Metzger (con apuestas por intentar mostrar que lo generativo y lo degenerativo no tienen una línea divisoria muy clara: una crítica además a las armas químicas), Jacques Villeglé (quien recoge imágenes de publicidades desgastadas en las paredes de Paris y las superpone en una suerte de alineación caótica), Manolo Valdés (cuyo trabajo consiste en superponer 
capas de lienzos de diferentes materiales, que dan la sensación de estar en pleno proceso de construcción como si no estuvieran terminados o estar en plena descomposición, como si estuvieran a punto de caerse), Braun Vega (quien pinta "encuentros imposibles" pues realiza un collage de imágenes que en apariencia serían imposibles de ver en la vida cotidiana). Con estas 4 experiencias, Bauman concluye:

La idea de belleza que informara el arte en la etapa de la modernidad sólida está pues en crisis porque transmite esa idea de estagnación: el fin del cambio, el fin de lo nuevo, de la experiencia y de la experimentación, el fin de la aventura. Esto confiere mayor peso a, y explica, lo que dije antes, a saber, que vivimos en un mundo saturado por la estética, pero un mundo en el que no hay objetos de arte, no hay obras de arte. (Bauman 2007: 47).

En una perspectiva como esta, por supuesto no cabe la lectura de formas alternativas de producción de sentido. Si en algo comprendo yo el papel del arte, es en su capacidad para hacer huella allí donde la industria cultural establece su dominio como estructura de representación incuestionable. Desde esta mirada no puede ser visible la emergencia de "arte otro" porque el saber se encuentra colonizado por el mito moderno.

\section{Imagen final: Arte "otro"}

Todas estas ideas, nos llevan a una última imagen que deseo problematizar. Si bien esta idea de lo líquido propio de la contemporaneidad es bastante ilustrativa y nos permite hacer duros cuestionamientos al modo de vida que hemos configurado, pienso existen formas de creación que no son necesariamente "líquidas desde esta perspectiva". Si bien es posible pensar que esta es una de las maneras en que el arte está pensando sus maneras de hacer, existen bastantes y potentes experiencias artísticas que vienen presentando maneras alternativas de pensar esas maneras "otras" de las que habla Arturo Escobar. Pensemos por ejemplo en las propuestas de la experiencia "in situ - ex situ: prácticas en comunidad" del centro cultural Moravia en la ciudad de Medellín en Colombia. Pensemos además en experiencias como wallpeople, la Red Latinoamericana de Arte y Transformación Social y otras tantas experiencias que están configurando estas maneras "otras" de relacionar el arte con la vida.

En general es un proceso que empiezo a indagar como un programa de investigación de largo plazo en el que deseo pensar este asunto del arte otro como configurador de lugares 
alternativos a la globalización hegemonizante. Muchas de estas experiencias pasan por formas de apropiación de las industrias culturales que generan formas de resistencia en las que se construyen relatos diversos sobre el mundo contemporáneo. En otras palabras, formas de hacer arte que no se agotan en la relación con los circuitos de circulación, sino que emprenden relaciones colaborativas de producción que generar posibilidades de autoenunciación que dan sentido a lo comunitario. Es por ello que no hablo de una tendencia específica del arte sino que me interesa nombrarlo como "arte otro" para significar una experiencia de producción de sentido que desplaza el eje del arte del museo y que se presenta como tendencias en la Estética relacional, el Arte Contextual, Arte dialógico, Arte comunitario o colaborativo, Artivismo, entre otros.

Todas estas experiencias en esta nuestra casa, hacen pensar que lo líquido en el arte es una manera de ser pero no su única alternativa. Si la estrategia o el lugar del marketing es el miedo, quizás el lugar del arte sea el amor.

\section{Bibliografía}

Bauman, Z. (2005): Vidas Desperdiciadas: La modernidad y sus parias. Buenos Aires: Paidos.

Bauman, Z. (2006): Modernidad Líquida. Buenos Aires: Fondo de Cultura Económica.

Bauman, Z. (2007): Arte, ¿líquido? Madrid: Sequitur.

Echeverría J (1994): Telépolis. Cosmopolitas domésticos. Barcelona: Ediciones Destino

Escobar, A. (2005): Más Allá del Tercer Mundo. Globalidad y Diferencia. Bogotá: Instituto Colombiano de Antropología e Historia.

Foucault (1967): Of Other Spaces: Utopias and Heterotopias. Recuperado de http://web.mit.edu/allanmc/www/foucault1.pdf. Consultado el 15/10/12

Garcia-Canclini, N. (2003): Culturas híbridas: Estrategias para entrar y salir de la Modernidad. Mexico: Grijalbo.

Heidegger M. (1994): ¿Qué quiere decir pensar? En: Conferencias y Artículos Barcelona: Ediciones del Serbal. 
Joseph, I. (1998): El derecho a la ciudad. La ciudad configurándose: dos paradigmas de la investigación. En: Metrópolis: espacio, tiempo y cultura. Revista Ciencias Humanas, No 24, Medellín, Universidad Nacional, Marzo de 1998.

Lanceros, P. (2007): La Estética de la Ciudad. Bilbao: Universidad de Deusto

Levy, P. (1999): ¿Qué es lo virtual? Barcelona: Paidos

Moreno, J. G. (1998): ¿Qué es un territorio? En: Revista de Ciencias Humanas \#24. Medellín: Universidad Nacional de Colombia

Pardo, J. L. (1991): Las Formas de la Exterioridad. Valencia: Pre-Textos

Steiner, G. (1992): Presencias Reales. Barcelona:

\section{Forma de citar este artículo en bibliografías}

Gómez Agudelo, J. (2013): "La pregunta por el lugar del arte en el mundo contemporáneo o cómo acercarse a una idea de 'arte otro', en Revista PANGEA, 4, páginas 161 a 173. Red Académica Iberoamericana de Comunicación. Recuperado el _ de __ de 2 de: http://www.revistapangea.org 